\title{
Thoracic endovascular aortic repair versus open surgery for type-B chronic dissection
}

\author{
Eric E. Roselli, MD
}

An aging population, increased awareness, high-resolution imaging, and improving access to care all mean that more people are being diagnosed with acute aortic dissection. A better understanding of the role of initial medical therapy, improved surgical techniques, and the addition of endovascular approaches to the treatment algorithm, have resulted in more patients surviving the acute phase of disease. During the chronic phase, patients with residual dissection are challenged by the competing risks of reoperation or death. Open repair for chronic type-B dissection can be performed safely but is a relatively morbid operation. For this reason, surgery is often postponed until patients develop very late complications. Despite encouraging results for thoracic endovascular aortic repair of acute type-B dissection, chronic type-B dissection poses unique challenges that make application of endovascular technology more difficult. As our understanding of the disease and its natural history evolves, the ways in which these 2 methods of treatment complement each other need to be better understood. The benefits and limitations of each therapy, and how and when to apply each in the setting of chronic distal dissection, are discussed. (J Thorac Cardiovasc Surg 2015;149:S163-7)

See related commentary on pages S168-9.

No patient should be considered cured of the disease. -E. Stanley Crawford, MD, on aortic dissection

Although great strides have been made in the past 50 years of treating aortic dissections, many of the early lessons learned by Dr Crawford and other pioneers hold true today. ${ }^{1}$ Descending aortic dissection is a lifelong disease and carries high morbidity and mortality. In the chronic state, dissections are managed medically with close imaging surveillance until complications such as aneurysmal degeneration warrant surgical intervention.

At first glance, thoracic endovascular aortic repair (TEVAR) and open surgery have been assessed as competitive therapies to treat distal aortic disease. ${ }^{2}$ More surgeons, and aortic centers of excellence, now have the skill set to offer both types of intervention. In the past year, TEVAR has received US Food and Drug Administration approval for the treatment of both acute and chronic aortic dissection. As our understanding of the disease and its natural history evolves, the ways in which these 2 methods of treatment complement each other need to be

\footnotetext{
From the Department of Thoracic and Cardiovascular Surgery, Heart and Vascular Institute, Cleveland Clinic, Cleveland, Ohio.

Disclosures: Dr Roselli serves as a consultant and investigator for Medtronic, Inc (Minneapolis, Minn), Cook (Bloomington, Ind), and Terumo (Ann Arbor, Mich).

Read at The American Association for Thoracic Surgery Aortic Symposium,

New York, New York, April 24-25, 2014.

Received for publication Oct 4, 2014; revisions received Oct 29, 2014; accepted for publication Nov 7, 2014.

Address for reprints: Eric E. Roselli, MD, Department of Thoracic and Cardiovascular Surgery, Cleveland Clinic, 9500 Euclid Ave/Desk J4-1, Cleveland, OH 44195 (E-mail: roselle@ccf.org).

$0022-5223 / \$ 36.00$

Copyright (c) 2015 by The American Association for Thoracic Surgery

http://dx.doi.org/10.1016/j.jtcvs.2014.11.028
}

better understood. The benefits and limitations of each therapy, and how and when to apply each in the setting of chronic distal dissection, are discussed.

\section{CHRONIC DISTAL DISSECTION PATIENTS}

An aging population, increased awareness, highresolution imaging, and improving access to care all mean that more people are being diagnosed with acute aortic dissection. A better understanding of the role of initial medical therapy, improved surgical techniques, and the addition of endovascular approaches to the treatment algorithm, have resulted in more patients surviving the acute phase of disease. Previously, the time course of aortic dissection was understood to be acute if it was within the first 14 days of the initial event; afterward, it was considered chronic. Appreciation is now growing for the multiple phases of hazard associated with dissection; as a result, hyperacute is now defined as within the first 24 hours, acute as within the first week, subacute as within the first 30 to 90 days, and chronic as after that.

A great majority of patients surviving acute events are left with a residual dissection. A subset develop complications resulting from disease progression that manifests as aneurysmal degeneration, rupture, or end-organ malperfusion. ${ }^{3,4}$ These complications occur in $20 \%-50 \%$ of patients, whether they initially present with a DeBakey type-3 dissection or survive the emergency proximal repair of a type- 1 dissection. One study reported a $60 \%$ incidence of progressive aortic dilatation, and a risk of rupture as high as $20 \%$ at a mean follow-up of $44.6 \pm 25.4$ months. ${ }^{5}$ These patients with complicated chronic descending thoracic dissection should be managed surgically, or with interventional therapy. ${ }^{3}$ Patients with uncomplicated chronic dissections are typically treated medically and followed until they develop 1 of these complications or die. The goal of each treatment modality is to prevent late aorta-related deaths. 


\section{Abbreviations and Acronyms}

ADSORB = acute dissection: stent graft or best

INSTEAD $=$ investigation of stent grafts in aortic dissection

TEVAR $=$ thoracic endovascular aortic repair

The nature of the disease in its chronic state is varied, and so the population is heterogeneous, making a fair comparison among treatment modalities difficult. Additionally, patency and degree of patency (ie, thrombosis, partial thrombosis, fully patent) of the false lumen are predictors of the need for reoperation, and of late survival. ${ }^{6,7}$

\section{OPEN-REPAIR OUTCOMES}

In a recent study of our experience at the Cleveland Clinic, we evaluated the results of open repair performed between 2000 and 2008 in 169 patients with descending aortic dissection who were deemed to be anatomically amenable to TEVAR. ${ }^{8}$ Most operations were performed with circulatory support and cerebrospinal fluid drainage. Resection was limited to the aneurysmal segment, and approximately half underwent thoracoabdominal repair. Many of these patients had undergone previous ascending, arch, and first-stage elephant trunk reconstruction. Operative mortality was $8 \%$, and neurologic complications occurred in $2.4 \%$. Survival at 1,2 , and 3 years was $82 \%, 78 \%$, and $75 \%$, respectively, and $14 \%$ required reintervention. At 5 years, an estimated $50 \%$ were either dead or had undergone a reintervention (Figure 1). The strongest risk factor for the occurrence of 1 of these composite adverse events was a larger-diameter aorta at the level of the diaphragm, suggesting that patients with late-stage disease or a more aggressive form of disease do worse.

Similarly, Koli and colleagues ${ }^{9}$ described their experience with 104 patients who underwent open repair of descending aortic dissection between 1994 and 2007. The mortality was $9.6 \%$; stroke occurred in $5.8 \%$, renal failure in $4.8 \%$, and tracheostomy was required in $14 \%$. The open approach is a morbid procedure. The estimated survival was $68 \%$ at 5 years, and although the authors stated that the survival approached that of age- and gender-matched controls after 1 year by landmark analysis (ie, eliminating the $22 \%$ first-year mortality), the survival curves separate again at about 4-5 years, with chronic dissection patients doing worse than the controls.

\section{IMPORTANCE OF A COMPETING-RISK ANALYSIS}

These late follow-up results emphasize the fact that chronic dissection patients have a lifelong disease. During the chronic phase, patients with residual dissection after acute surgical, medical, or endovascular therapy are challenged by the competing risks of reoperation or death. Open repair for chronic type-B dissection can be performed safely but is a relatively morbid operation. Many physicians and surgeons are hesitant to recommend surgery until it is deemed absolutely necessary, and patients fear open distal aortic repair. For this reason, surgery is often postponed until patients develop very late complications. This deferred approach to treating chronic aortic dissection should change if we are going to make progress in changing the long-term outcomes for patients who survive the acute phase of aortic dissection.

\section{TEVAR FOR COMPLICATED CHRONIC DISSECTION}

As experience with TEVAR has grown, its use has been expanded to patients with complicated chronic dissections, although the devices have only recently been approved for that indication. This approval was based mostly on data demonstrating a lower acute risk of the endovascular procedure as compared with open repair. Late outcome data for TEVAR in chronic aortic dissection are limited. In a study that was concurrent with the previously mentioned open series, we published our outcomes after TEVAR in patients with complicated chronic type-B dissection. ${ }^{10}$ Patients in the open surgical series were younger compared with those treated with TEVAR, but they were more likely to have extensive dissection extending through the abdominal aorta. ${ }^{8}$ The TEVAR series included many patients with the dissection limited to the thoracic aorta.

Operative mortality in our TEVAR patients was $5 \%$, and survival at 1,2 , and 3 years was $86 \%, 82 \%$, and $80 \%$, respectively, but reintervention was required in $22 \%$. In both the open repair and TEVAR studies, freedom from adverse events (ie, death or vascular reoperation) was similar-about $55 \%$ at 5 years in the TEVAR paper, and $50 \%$ in the open series. The diameter of the aorta at the level of the diaphragm was predictive of the risk of death or reintervention in the TEVAR experience, just as was seen in the open series.

Despite encouraging results of TEVAR for acute type-B dissection, chronic type-B dissection poses unique challenges that make application of endovascular technology more difficult. The delivery and deployment is usually carried out using a transfemoral approach under fluoroscopic guidance. The primary objective is to cover the proximal entry tear and expand the dissected true lumen. Achieving this objective usually requires positioning of the device in the distal aortic arch, and left subclavian artery coverage is necessary about $40 \%$ of the time. ${ }^{11}$ Coverage of the proximal entry tear and expansion of the true lumen promote thrombosis of the false lumen, with the hope of reverse remodeling of the aorta, but this process is inconsistent. Many 


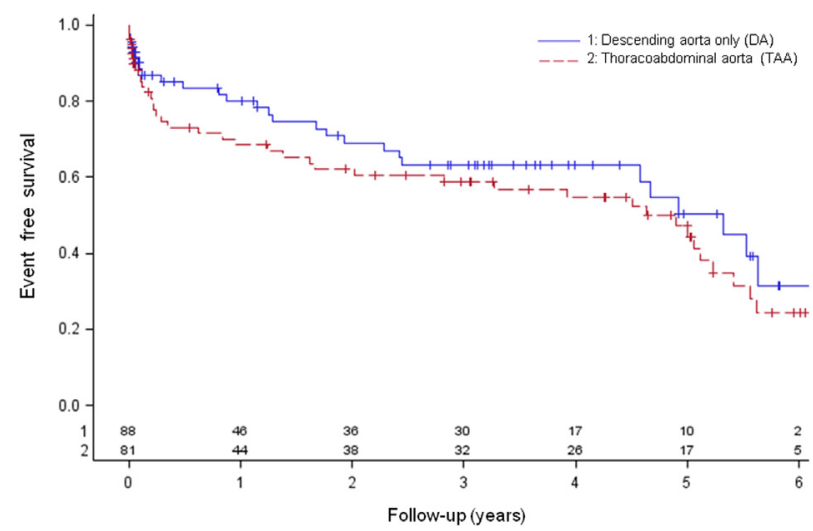

FIGURE 1. Kaplan-Meier estimate of event-free survival (freedom from all-cause mortality and vascular reintervention) by extent of repair, expressed as probability with number at risk. Reprinted with permission. ${ }^{8}$

authors have confirmed this inconsistency in the occurrence of thromboexclusion. ${ }^{12-14}$

With time, the dissection flap thickens and becomes less mobile, and the distal re-entry tears mature into stable communications between the 2 lumens. Although the process of thrombosis may occur slowly over time, evidence has shown that it needs to be complete to lead to aortic shrinkage and a reversal of the natural history of the disease. ${ }^{15,16}$ In our series of TEVAR for chronic dissection, complete false lumen thrombosis occurred in $78 \%$ of those in whom the dissection was limited to the thoracic aorta, but in only $13 \%$ of those with more-extensive dissection (Figure 2). ${ }^{10}$

The incomplete healing of the aorta after TEVAR accounts for the need for reintervention. In a recently published compilation of data from several prospectively

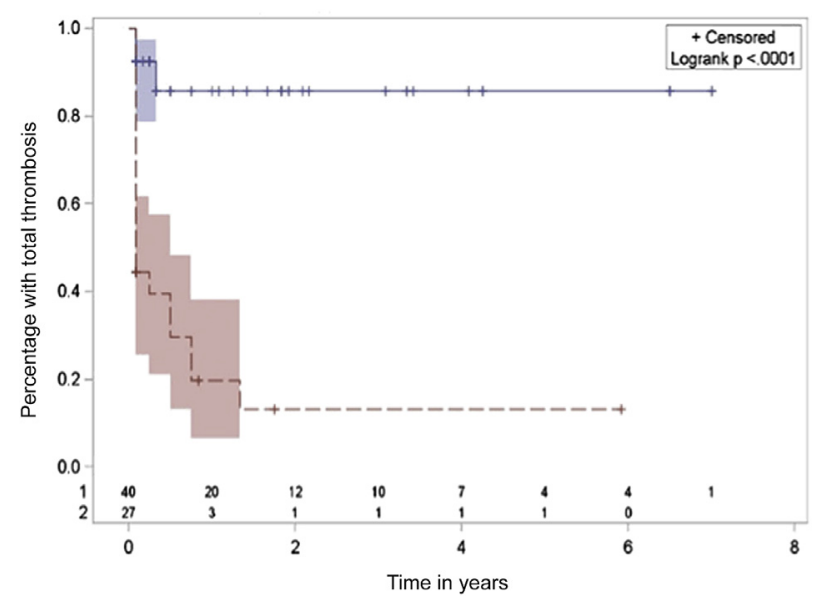

FIGURE 2. Percentage of false lumen complete thrombosis after thoracic endovascular aortic repair for chronic aortic dissection by extent of aorta dissected. Limited extent (ie, thoracic aorta only) is shown in blue and extensive dissection is shown in red. Reprinted with permission. ${ }^{10}$ collected registries, the diagnosis of aortic dissection as an indication for TEVAR was correlated with a much higher need for reintervention than the diagnosis in those with degenerative aneurysm. ${ }^{11}$

\section{TEVAR FOR UNCOMPLICATED CHRONIC DISSECTION}

In an effort to determine whether earlier treatment with stent grafting could improve outcomes for patients with uncomplicated chronic (albeit early, ie, 2-52 weeks) aortic dissection, the INSTEAD (investigation of stent grafts in aortic dissection) trial was designed as a randomized controlled trial comparing TEVAR $(n=72)$ with optimal medical management $(n=68)$. More false lumen thrombosis and aortic remodeling occurred in TEVAR patients, but the treatments did not have a statistically significant differential impact on survival during the initial 2 years of follow-up. At 2 years, there was a $20 \%$ cross-over rate from medical therapy to TEVAR. ${ }^{17}$ The follow-up of these patients has been extended to 5 years in the recently published INSTEAD XL trial and has again demonstrated aortic remodeling to have occurred in $79 \%$ of TEVAR patients versus only $10 \%$ of those in the medical therapy group $(P<.0001){ }^{18}$ The all-cause mortality was still not significantly different between groups at this 5-year analysis point $(P=.140)$, but the curves appear to cross at about 3 years.

There was a statistically significant benefit to TEVAR with regard to aortic-related deaths, and in all of the landmark analyses. These studies are probably underpowered, because the authors underestimated the benefits of optimal medical therapy, which is less commonly delivered in real-world situations. Furthermore, the potential complications associated with early stent grafting may be difficult to overcome during a short period of follow-up. The patients in this early study received older-generation devices, and the procedures were performed at multiple centers with variable levels of experience and quality. Fortunately, the devices and delivery systems, as well as the understanding of potential complications, have improved since this early experience. With additional studies, such as the ADSORB (acute dissection: stent graft or best) trial, and increasing experience with modern dissection-approved devices at centers of excellence, it is likely that a subset of patients will be identified who have uncomplicated dissection, are at high risk for early complications, and will benefit from TEVAR during the subacute phase of disease.

\section{RETROGRADE DISSECTION}

From the growing experience with TEVAR in dissections, it has become apparent that retrograde ascending 
aortic dissection is an important life-threatening complication of this procedure. It must be recognized as such and avoided if possible. A large systematic review ${ }^{19}$ of more than 40 studies and nearly 10,000 patients reported the occurrence of this complication in $1.7 \%$, and mortality after its occurrence of $33.6 \%$. These findings were consistent with prior studies of the same problem. ${ }^{20,21}$ It was much more common when the indication for TEVAR was descending dissection (4\%) rather than degenerative aneurysm $(0.9 \%)$, and during the acute phase $(8.4 \%)$ versus chronic $(3 \%) .{ }^{19}$ The average amount of oversizing in those with retrograde dissection was $22 \%$, versus only $10.3 \%$ in the others $(P<.0001)$. Risk-factor analysis of the data demonstrated that the occurrence of retrograde dissection was directly correlated with the extent of oversizing of the devices in relation to the proximal landing zone such that for each percentage point of oversizing greater than $9 \%$, the risk for retrograde dissection increased by $14 \%$.

In addition, we have found an incidence of retrograde dissection after TEVAR in about $1.8 \%$ of our patients, and this was most commonly found in patients treated for dissection. In our experience with this complication, however, only 1 patient died, and this death occurred before transfer to the operating room. In the 14 patients who were stable enough for operative intervention, no deaths occurred, and the stent-graft device was maintained in all patients using a reverse frozen elephant trunk repair strategy. ${ }^{22}$

\section{NEED FOR ADJUNCTIVE THERAPY AND BETTER DEVICES}

The most common complications after descending stent grafting for chronic aortic dissection relate to issues at the landing zones. Proximally, this may manifest as retrograde dissection as described, or type-1 endoleak. Distally, the most common late problem is due to persistent perfusion of the false lumen from distal re-entry tears, which can promote further aneurysmal degeneration and eventual rupture of the at-risk aorta (Figure 3). To address these complications, we have used both the open and endovascular approach, or a combination. These options include the use of custom, branched graft devices, off-label delivery of devices into the false lumen for occlusive purposes, visceral bypasses with extended aortic coverage, open distal aortic fenestration in combination with elephant trunk creation to optimize landing zones, and direct conversion to open repair. ${ }^{23-28}$

\section{CONCLUSIONS}

As our understanding and standardized treatment for acute dissection improve, we will see a growth in late survivors and an increase in the need for treatment of dissection during the chronic phase. A growing body of data suggests

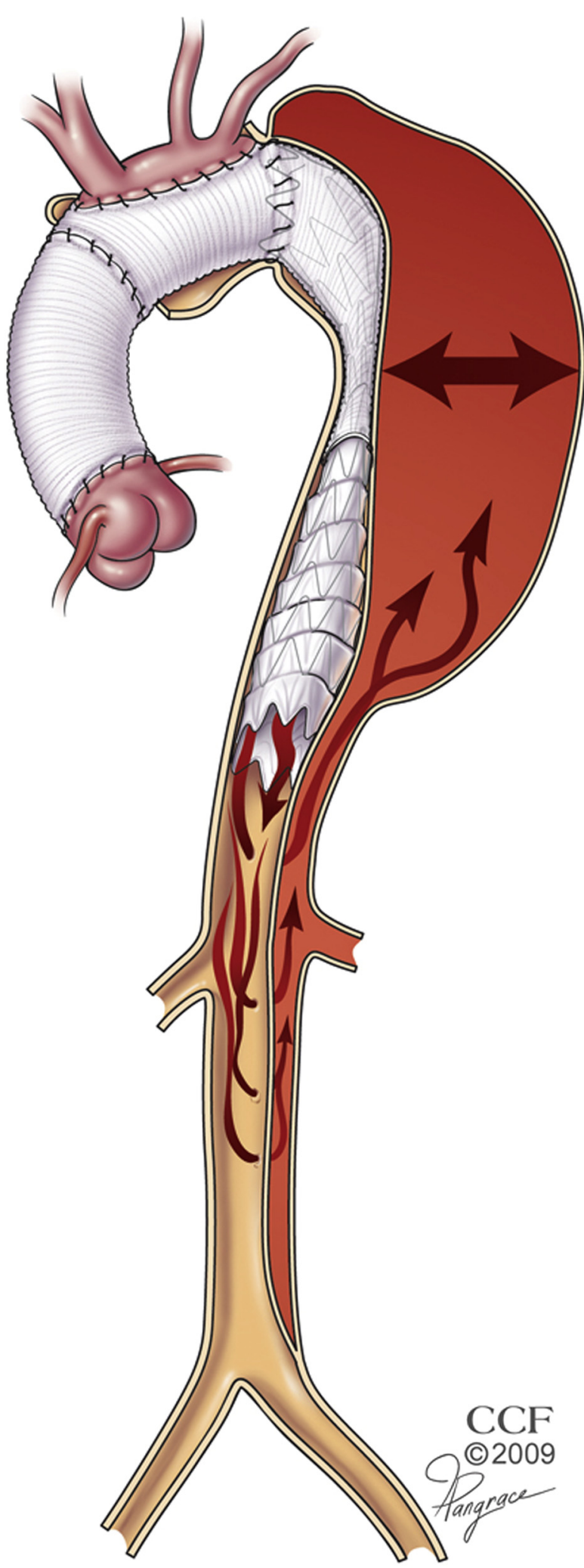

FIGURE 3. Illustration demonstrating the problem of retrograde false lumen perfusion that commonly occurs in patients with chronic aortic dissection and prohibits complete healing and reverse remodeling. Reprinted with permission. ${ }^{23}$ 
that patients will fare better with earlier and moreaggressive therapy. The use of stent grafting may safely expand these treatment options to more patients at an earlier phase of degeneration. The development of better diseasespecific stent grafts and adjunctive devices should make endovascular treatment the primary option, even for patients with later-stage chronic disease. As our appreciation for the limitations and benefits of open and endovascular repair improves, so should our understanding of how these approaches serve as complementary methods to treating a very complex pathology.

\section{References}

1. Crawford ES. The diagnosis and management of aortic dissection. JAMA. 1990; 264:2537-41.

2. Cheng D, Martin J, Shennib H, Dunning J, Muneretto C, Schueler S, et al. Endovascular aortic repair versus open surgical repair for descending thoracic aortic disease: a systematic review and meta-analysis of comparative studies. $J$ Am Coll Cardiol. 2010;55:986-1001.

3. Hiratzka LF, Bakris GL, Beckman JA, Bersin RM, Carr VF, Casey DE Jr, et al. ACCF/AHA/AATS/ACR/ASA/SCA/SCAI/SIR/STS/SVM guidelines for the diagnosis and management of patients with thoracic aortic disease: executive summary: A report of the American College of Cardiology Foundation/American Heart Association Task Force on Practice Guidelines, American Association for Thoracic Surgery, American College of Radiology, American Stroke Association, Society of Cardiovascular Anesthesiologists, Society for Cardiovascular Angiography and Interventions, Society of Interventional Radiology, Society of Thoracic Surgeons, and Society for Vascular Medicine. Circulation. 2010; $121: \mathrm{e} 266-369$.

4. Subramanian S, Roselli EE. Thoracic aortic dissection: long-term results of endovascular and open repair. Semin Vasc Surg. 2009;61-8.

5. Miyahara S, Mukohara N, Fukuzumi M, Morimoto N, Murakami H, Nakagiri K, et al. Long-term follow-up of acute type B aortic dissection: ulcer-like projections in thrombosed false lumen play a role in late aortic events. J Thorac Cardiovasc Surg. 2011;142:e25-31.

6. Fattouch K, Sampognaro R, Navarra E, Caruso M, Pisano C, Coppola G, et al. Long-term results after repair of type a acute aortic dissection according to false lumen patency. Ann Thorac Surg. 2009;88:1244-50.

7. Tsai TT, Evangelista A, Nienaber CA, Myrmel T, Meinhardt G, Cooper JV, et al. Partial thrombosis of the false lumen in patients with acute type B aortic dissection. N Engl J Med. 2007;357:349-59.

8. Pujara A, Roselli EE, Hernandez A, Vargas Abello LM, Burke JM, Svensson LG, et al. Open repair of chronic distal aortic dissection in the endovascular era: implications for disease management. J Thorac Cardiovasc Surg. 2012;144:866-73.

9. Zoli S, Etz CD, Roder F, Mueller CS, Brenner RM, Bodian CA, et al. Long-term survival after open repair of chronic distal aortic dissection. Ann Thorac Surg. 2010:89:1458-66

10. Kang W, Greenberg RK, Mastracci T, Eagleton MJ, Hernandez AV, Pujara AC, et al. Endovascular repair of complicated chronic distal aortic dissections: intermediate outcomes and complications. J Thorac Cardiovasc Surg. 2011;142: 1074-83.

11. Patterson B, Holt P, Nienaber C, Cambria R, Fairman R, Thompson M. Report from the Medtronic Thoracic Endovascular Registry (MOTHER) database. Circulation. 2013;127:24-32.
12. Scali ST, Feezor RJ, Chang CK, Stone DH, Hess PJ, Martin TD, et al. Efficacy of thoracic endovascular stent repair for chronic type B aortic dissection with aneurysmal degeneration. J Vasc Surg. 2013;58:10-7.

13. Lombardi JV, Cambria RP, Nienaber CA, Chiesa R, Teebken O, Lee A, et al. Prospective multicenter clinical trial (STABLE) on the endovascular treatment of complicated type B aortic dissection using a composite device design. $J$ Vasc Surg. 2012;55:629-40.

14. Parsa CJ, Williams JB, Battacharya SD, Wolfe WG, Daneshmand MA, McCann RL, et al. Midterm results with thoracic endovascular aortic repair for chronic type B aortic dissection with associated aneurysm. J Thorac Cardiovasc Surg. 2011;141:322-7.

15. Andecheh ID, Donayre C, Othman F, Walot I, Kopchok G, White R. Patient outcomes and thoracic aortic volume and morphologic changes following thoracic endovascular aortic repair in patients with complicated chronic type B aortic dissection. J Vasc Surg. 2012;56:644-50; discussion 650.

16. Mani K, Clough RE, Lyons OT, Bell RE, Carrell TW, Zayed HA, et al. Predictors of outcome after endovascular repair for chronic type B dissection. Eur J Vase Endovasc Surg. 2012;43:386-91.

17. Nienaber CA, Rousseau H, Eggebrecht H, Kische S, Fattori R, Rehders TC, et al. Randomized comparison of strategies for type B aortic dissection: the INvestigation of STEnt Grafts in Aortic Dissection (INSTEAD) trial. Circulation. 2009; 120:2519-28.

18. Nienaber CA, Kische S, Rousseau H, Eggebrecht H, Rehders TC, Kundt G, et al INSTEAD-XL trial. Endovascular repair of type B aortic dissection: long-term results of the randomized investigation of stent grafts in aortic dissection trial. Circ Cardiovasc Interv. 2013;6:407-16.

19. Canaud L, Ozdemir BA, Patterson BO, Holt PJ, Loftus IM, Thompson MM. Retrograde aortic dissection after thoracic endovascular aortic repair. Ann Surg. 2014;260:389-95.

20. Dong ZH, Fu WG, Wang YQ, Guo da Q, Xu X, Ji Y, et al. Retrograde type A aortic dissection after endovascular stent graft placement for treatment of type B dissection. Circulation. 2009;119:735-41.

21. Eggebrecht H, Thompson M, Rousseau H, Czerny M, Lönn L, Mehta RH, et al. Retrograde ascending aortic dissection during or after thoracic aortic stent graf placement: insight from the European registry on endovascular aortic repair complications. Circulation. 2009;120(11 Suppl):S276-81.

22. Idrees J, Arafat A, Johnston DR, Svensson LG, Roselli EE. Repair of retrograde ascending dissection after descending stent grafting. J Thorac Cardiovasc Surg. 2014;147:151-4.

23. Roselli EE, Sepulveda E, Pujara AC, Idrees J, Nowicki E. Distal landing zone open fenestration facilitates endovascular elephant trunk completion and false lumen thrombosis. Ann Thorac Surg. 2011;92:2078-84.

24. Roselli EE, Abdel-Halim M, Johnston DR, Soltesz EG, Greenberg RK, Svensson LG, et al. Open aortic repair after prior thoracic endovascular aortic repair. Ann Thorac Surg. 2014;97:750-6.

25. Roselli EE, Subramanian S, Sun Z, Idrees J, Nowicki E, Blackstone EH, et al. Endovascular versus open elephant trunk completion for extensive aortic disease. J Thorac Cardiovasc Surg. 2013;146:1408-16; discussion 1416-7.

26. Vivacqua A, Albacker TB, Roselli EE. Hybrid thoracoabdominal aneurysm repair with antegrade visceral debranching from the ascending aorta: concomitant cardiac surgery and stent-grafting. Ann Thorac Surg. 2011;92: 2275-7.

27. Kitagawa A, Greenberg RK, Eagleton MJ, Mastracci TM, Roselli EE. Fenestrated and branched endovascular aortic repair for chronic type B aortic dissection with thoracoabdominal aneurysms. J Vasc Surg. 2013;58:625-34.

28. Roselli EE, Idrees J, Reside J, Shafii S. Use of covered stent devices for false lumen embolization in chronic dissection: a novel approach. Ann Thorac Surg. 2014:98:737-9. 